\title{
MONOTONE ITERATIVE TECHNIQUE FOR $S$-ASYMPTOTICALLY PERIODIC PROBLEM OF FRACTIONAL EVOLUTION EQUATION WITH FINITE DELAY IN ORDERED BANACH SPACE
}

\author{
QIANG LI* AND MEI WEI
}

Abstract. In this paper, we devote to considering $S$-asymptotically periodic problem of fractional evolution equation with delay in ordered Banach space. Under some weaker assumptions, we construct monotone iterative method in the presence of the lower and upper solutions to the delayed fractional evolution equation, and obtain the existence of maximal and minimal $S$-asymptotically periodic mild solutions. Finally, we present two examples to illustrate the feasibility of our abstract results.

Mathematics subject classification (2020): 34K30, 34K37, 35R11, 47H07, 47H08.

Keywords and phrases: $S$-asymptotically periodic mild solutions, fractional evolution equation, monotone iterative technique, positive $C_{0}$-semigroup, measure of noncompactness, finite delay.

\section{REFERENCES}

[1] O. Agrawal, J. Sabatier, J. Tenreiro, Advances in fractional calculus, Springer, Dordrecht, 2007.

[2] H. AmANN, Nonlinear operators in ordered Banach spaces and some applicitions to nonlinear boundary value problem, In: Nonlinear operators and the Calculus of Variations, Lecture Notes in Mathmematics, Springer-Verlag, Berlin and New YorK, 1976, pp. 1-55.

[3] H. Amann, Periodic solutions of semilinear parabolic equations, In: L. Cesari, R. Kannan, R. Weinberger (Eds.), Nonlinear Anal., A Collection of Papers in Honor of Erich H. Rothe, New York: Academic Press, 1978: 1-29.

[4] E. BAZHLEKova, The abstract Cauchy problem for the fractional evolution equation, Fract. Calc. Appl. Anal., 1 (1998), 255-270.

[5] J. Banas, K. Goebel, Measure of Noncompactness in Banach Spaces, Lect. Notes Pure Appl. Math., vol. 60, New York: Marcel Dekker, 1980.

[6] J. Banasiak, L. Arlotti, Perturbations of Positive Semigroups with Applications, London: Springer-Verlag, 2006.

[7] Y. K. Chang, V. Kavitha, M. Mallika Arjunan, Existence and uniqueness of mild solutions to a semilinear integro-differential equations of fractional order, Nonlinear Anal., 71 (2009), 5551-5559.

[8] P. CHEN, Y. LI, Existence of mild solutions for fractional evolution equations with mixed monotone nonlocal conditions, Z. Angew. Math. Phys., 65 (2014), 711-728.

[9] P. CHEN, Y. LI, Q. LI, Existence of mild solutions for fractional evolution equations with nonlocal initial conditions, Ann. Polon. Math., 110 (2014), 13-24.

[10] P. Chen, Y. LI, Mixed monotone iterative technique for a class of semilinear impulsive evolution equations in Banach spaces, Nonlinear Anal., 74 (2011), 3578-3588.

[11] P. Chen, Y. LI, Monotone iterative technique for a class of semilinear evolution equations with nonlocal conditions, Results Math., 63 (2013), 731-744.

[12] P. Chen, Y. LI, H. YANG, Perturbation method for nonlocal impulsive evolution equations, Nonlinear Anal. Hybrid Syst., 8 (2013), 22-30.

[13] P. Chen, X. Zhang, Y. LI, Iterative method for a new class of evolution equations with noninstantaneous impulses, Taiwanese J. Math., 21 (2017), 913-942. 
[14] P. Chen, X. ZHANG, Y. Li, Fractional non-autonomous evolution equation with nonlocal conditions, J. Pseudo-Differ. Oper. Appl., 10 (2019), 955-973.

[15] P. Chen, X. ZHANG, Y. Li, Existence and approximate controllability of fractional evolution equations with nonlocal conditions via resolvent operators, Fract. Calcu. Appl. Anal., 23 (2020), $268-291$.

[16] P. Chen, X. Zhang, Y. LI, Cauchy problem for fractional non-autonomous evolution equations, Banach J. Math. Anal., 14 (2020): 559-584.

[17] C. Cuevas, J. SouzA, Existence of S-asymptotically $\omega$-periodic solutions for fractional order functional integro-differential equations with infinite delay, Nonlinear Anal., 72 (2010), 1683-1689.

[18] C. Cuevas, H. R. Henríquez, H. Soto, Asymptotically periodic solutions of fractional differential equations, Appl. Math. Comput., 236 (2014), 524-545.

[19] K. Deimling, Nonlinear Functional Analysis, New York: Springer-Verlag, 1985.

[20] T. Diagana, G. M. Mophou, G. M. N'GuÈrèKatA, On the existence of mild solutions to some fractional integro-differential equations, Electron. J. Qual. Theory Differ. Equ., 58, (2010), 1-17.

[21] Y. DU, Fixed points of increasing operators in Banach spaces and applications, Appl. Anal., 38 (1990), 1-20.

[22] S. Du, V. Lakshmikantham, Monotone iterative technique for differential equations in Banach spaces, J. Math. Anal. Appl., 87 (1982), 454-459.

[23] M. M. EI-BorAI, Some probability densities and fundamental solutions of fractional evolution equations, Chaos Solitons Fractals, 14 (2002), 433-440.

[24] D. Guo, J. Sun, Ordinary Differential Equations in Abstract Spaces, Jinan: Shandong Science and Technology, 1989 (in Chinese).

[25] D. GuO, X. LIU, Extremal solutions for a boundary value problem of $n$ th-order impulsive integrodifferential equations in a Banach space, Dyn. Contin. Discrete Impuls. Syst. Ser. A Math. Anal., 13 (2006), 599-619.

[26] H. P. HEINZ, On the behaviour of measure of noncompactness with respect to differentiation and integration of vector-valued functions, Nonlinear Anal., 7 (1983), 1351-1371.

[27] H. R. Henríquez, M. PIERri, And P. TÁBoAs, On S-asymptotically $\omega$-periodic functions on Banach spaces and applications, J. Math. Anal. Appl., 343 (2008), 1119-1130.

[28] T. Ke, N. LoI, V. OBUKhovs KiI, Decay solutions for a class of reactional differential variational inequalities, Fract. Calc. Appl. Anal., 18 (2015), 531-553.

[29] A. Kilbas, H. Srivastava, J. Trujillo, Theory and Applications of Fractional Differential Equations, Elsevier Science BV, (2006).

[30] A. A Kilbas, H. M. Srivastava, J. J. Trujillo, Theory and applications of fractional differential equations, In: van Mill, J. (ed.) North-Holland Mathematics Studies, vol. 204. Elsevier Science B. V., Amsterdam 2006.

[31] I. KIM, K. KIM, S. LIM, An $L_{q}\left(l_{p}\right)$-theory for the time fractional evolution equations with variable coefficients, Adv. Math., 306 (2017), 123-176.

[32] B. LI, H. GoU, Monotone iterative method for the periodic boundary value problems of impulsive evolution equations in Banach spaces, Chaos Solitons Fractals, 110 (2018), 209-215.

[33] F. Li, J. LIANG, H. WANG, S-asymptotically $\omega$-periodic solution for fractional differential equations of order $q \in(0,1)$ with finite delay, Adv. Difference Equ., 2017, Paper No. 83, 14 pp.

[34] F. LI, H. WANG, S-asymptotically $\omega$-periodic mild solutions of neutral fractional differential equations with finite delay in Banach space, Mediterr. J. Math., 14 (2017), 57.

[35] Y. LI, The positive solutions of abstract semilinear evolution equations and their applications, Acta Math. Sin., 39 (1996), 666-672 (in Chinese).

[36] Y. LI, Periodic solutions of semilinear evolution equations in Banach spaces, Acta Math. Sin., 41 (1998), 629-636 (in Chinese).

[37] Y. Li, Positive periodic solutions of first and second order ordinary differential equations, Chin. Ann. Math., 25 (2004), 413-420.

[38] Q. LI, Y. LI, Monotone iterative technique for second order delayed periodic problem in Banach spaces, Appl. Math. Comput., 270 (2015), 654-664.

[39] Q. LI, Y. LI, P. CHEN, Existence and uniqueness of periodic solutions for parabolic equation with nonlocal delay, Kodai Math. J., 39 (2016), 276-289.

[40] R. NAGEL, One-parameter Semigroups of Positive Operators, Lecture Notes in Math. vol. 1184, Berlin: Springer-Verlag, 1986. 
[41] A. PAZY, Semigroup of linear operators and applications to partial differential equations, SpringerVerlag, New York, 1993.

[42] M. PIERRI, On S-asymptotically $\omega$-periodic functions and applications, Nonlinear Anal., 75 (2012), 651-661.

[43] I. Podlubny, Fractional Differential Equations, Academic Press, San Diego, Calif, USA, 1999.

[44] L. REN, J. WANG, M. FEČKAN, Asymptotically periodic solutions for Caputo type fractional evolution equations, Fract. Calc. Appl. Anal., 21 (2018), 1294-1312.

[45] W. Ruess, W, Summers, Operator semigroups for functional differential equations with delay, Trans. Amer. Math. Soc., 341 (1994), 695-719.

[46] J. Sun, Z. ZHAO, Extremal solutions of initial value problem for integro-differential equations of mixed type in Banach spaces, Ann. Differ. Equations, 8 (1992), 469-475.

[47] R. WANG, D. CHEN, T. XIAO, Abstract fractional Cauchy problems with almost sectorial operators, Journal of Differential Equations, 252 (2012), 202-235.

[48] J. WANG, Y. ZHOU, A class of fractional evolution equations and optimal controls, Nonlinear Anal. Real World Appl., 12 (2011), 263-272.

[49] H. YE, J. GAO, Y. Ding, A generalized Gronwall inequality and its application to a fractional differential equation, J. Math. Anal. Appl., 328 (2007), 1075-1081.

[50] Y. ZHOU, F. JiAO, Existence of mild solutions for fractional neutral evolution equations, Comput. Math. Appl., 59 (2010), 1063-1077.

[51] Y. Zhou, Basic Theory of Fractional Differential Equations, World Scientific, Singapore, 2014.

[52] Y. ZHou, Fractional Evolution Equations and Inclusions: Analysis and Control, Elsevier, Academic Press, 2016. 